\title{
Dalhousie University medical school faces probation
}

$\mathrm{T}$

he undergraduate medical education program at Dalhousie University in Halifax, Nova Scotia, has been provisionally placed on probation (pending the outcome of an appeal) for failing to meet the accrediting requirements of the Liaison Committee for Medical Education, one of two accrediting authorities for medical schools in Canada and the United States.

Dalhousie will appeal the decision this fall. Should that appeal fail, it will have 24 months to correct the identified deficiencies or lose its accreditation.

Dalhousie's program was jointly reviewed earlier this year by the Liaison Committee for Medical Education and the Committee on Accreditation of Canadian Medical Schools. The Canadian team found the school noncompliant in 12 of 132 measures and indicated it would return in a year to assess progress. The American team, however, determined that Dalhousie was noncompliant in 17 areas and opted not to issue an accreditation seal of approval.

Issues identified by the American team related mainly to curriculum management, monitoring and evaluation. Failing grades were also given for failing to upgrade computer databases and for failing to provide the school's chief administrative officer with sufficient resources and authority to manage and assess the curriculum.

The school acknowledges that many of the identified issues need addressing. For example, Dean of Medicine Dr. Tom Marrie agrees with the need to map curriculum so that the range, breadth and frequency of subjects covered over the course of the undergraduate program are easily identified and understood.

But he does not agree with the liaison committee's conclusion that Dalhousie lacks an appropriate program to help residents with their teaching skills. "A number of years ago," he says, "it was determined we needed to

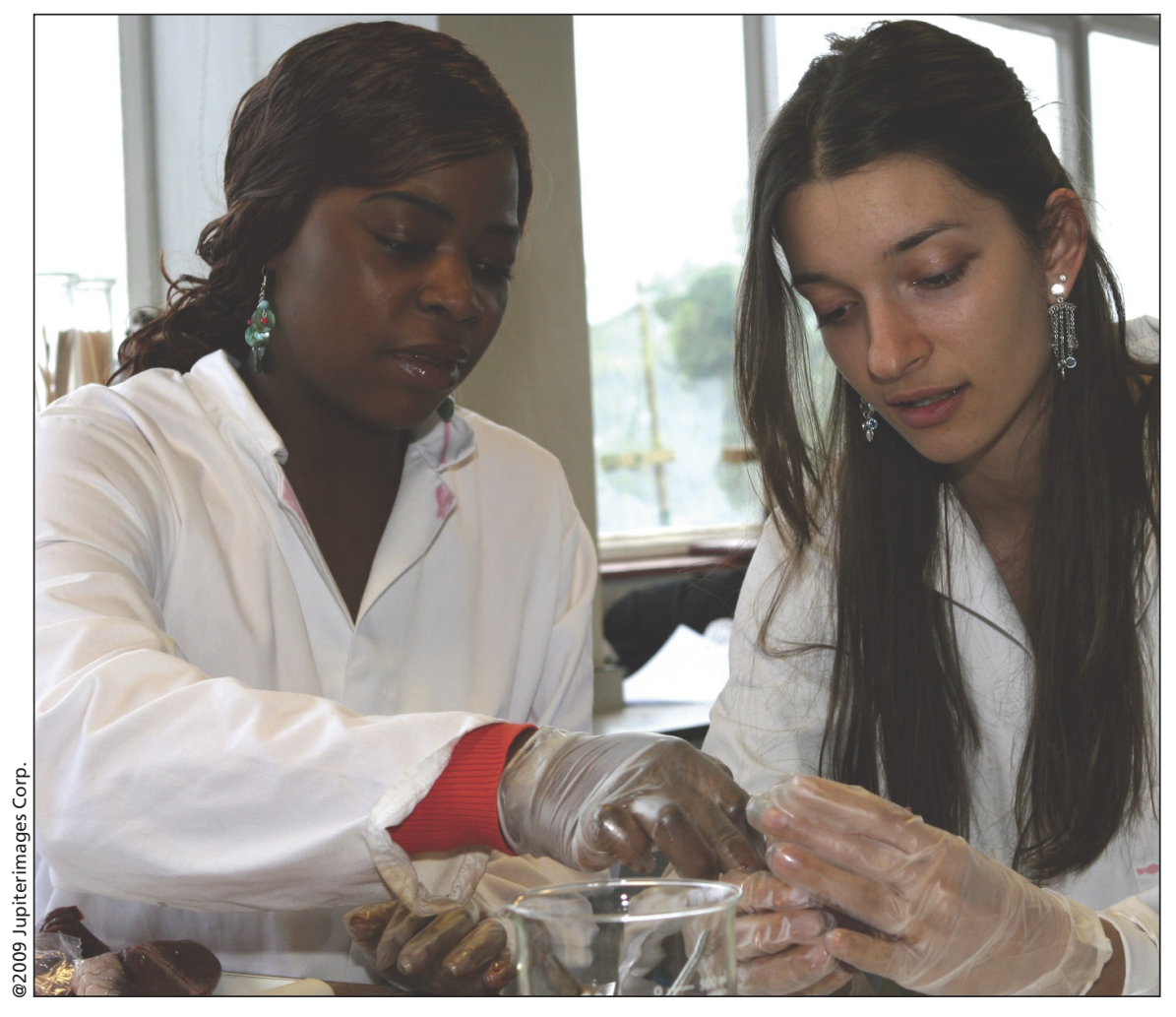

Dalhousie University medical graduates consistently score in the top quartile of Canadian medical students in national licensure exams, according to Dean of Medicine Dr. Tom Marrie. But accreditation bodies claim the program has many problems, mainly related to curriculum management, monitoring and evaluation.

teach the residents how to teach. We have a program for that, an elective that covers in-depth instruction, and individual programs have instructional elements."

The US committee also took issue with the amount of locker space at one hospital where students are placed. Marrie calls that "irrelevant to the product at the end, but students complain and it is one of the standards."

Dalhousie's appeal will be heard in Chicago in October. Marrie aims to reduce the number of noncompliant areas in hopes of keeping full accreditation status. But he's not certain what the magic number is, although he notes "if you're noncompliant with more than 10 , you get the indication they're not pleased with you."
Marrie believes Dalhousie will have to reduce the number of areas of noncompliance by at least five to eliminate the threat of probation. As part of its strategy, Dalhousie is also launching a curriculum review.

Should Dalhousie's appeal fail, it must promptly notify all enrolled students, those recently accepted and all applicants of its accreditation status, says Dr. Dan Hunt, Liaison Committee for Medical Education cosecretary and senior director, accreditation services with the Association of American Medical Colleges in Washington, DC.

Ironically, it's the second time that Marrie, who became dean in September, has had to deal with the possibility of probation - and losing accreditation. He went through the same situa- 
tion as dean of medicine and dentistry at the University of Alberta in Edmonton in 2005.

"At the University of Alberta, the medical staff came together and the students were wonderful," Marrie recalls. The precarious situation "didn't hurt us at all. ... In fact, it made us stronger."
Marrie also notes that Dalhousie received the highest accreditation ranking in its past two Liaison Committee for Medical Education surveys, in 1995 and 2002. "Since then, the performance of our graduating students has actually improved," he says. "Dalhousie's 2009 graduating class led the country in obtaining their first choice of residency placements in the national competition organized by the Canadian Resident Matching Service. Our Dalhousie medical graduates also consistently score in the top quartile of Canadian medical students in national licensure exams." — donalee Moulton, Halifax, NS

DOI:10.1503/cmaj.109-3019 